\title{
CARBAPENEM-RESISTANT ACINETOBACTER BAUMANNII OUTBREAK AT UNIVERSITY HOSPITAL
}

\author{
E.H. Takagi ${ }^{1}$; N. Lincopan ${ }^{1}$; V.C. Cassettari² ${ }^{2}$ L.F. Passadore ${ }^{3}$; E.M. Mamizuka ${ }^{1,2}$; M.B. Martinez ${ }^{1,2,3}$ \\ ${ }^{1}$ Laboratório de Microbiologia Clínica, Faculdade de Ciências Farmacêuticas, Universidade de São Paulo, São Paulo, SP, Brasil; \\ ${ }^{2}$ Comitê de Controle de Infecção Nosocomial, Hospital Universitário, Universidade de São Paulo, São Paulo, SP, Brasil; \\ ${ }^{3}$ Serviço de Laboratório Clínico, Hospital Universitário, Universidade de São Paulo, São Paulo, SP, Brasil
}

Submitted: June 03, 2008; Returned to authors for corrections: July 07, 2008; Approved: February 14, 2009.

\section{SHORT COMMUNICATION}

\begin{abstract}
Nineteen clonally related imipenem-resistant Acinetobacter baumannii isolates were recovered from eight

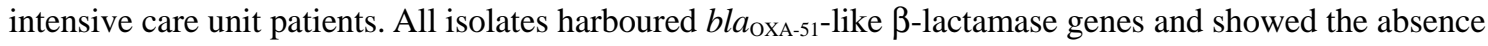
of $22 \mathrm{kDa}$ fraction in outer membrane porin profile analysis. It suggests a combination of two mechanisms as responsible for carbapenem-resistant phenotypes.
\end{abstract}

Key words: Acinetobacter, bla $a_{\mathrm{OXA}}$-type genes, carbapenemases, nosocomial infection, Brazil

\section{INTRODUCTION}

In Brazilian hospitals, multidrug-resistant (MDR) Acinetobacter baumannii constitute a serious cause of nosocomial infection, comprising $8.8 \%$ of the total nosocomial bacterial isolates that cause infections in ICU patients, according to the MYSTIC Program Brazil (11). In this respect, carbapenems remain as the widest spectrum therapeutic option for treatment of such infections. However, resistance to these antimicrobial agents has increased, resulting in the use of potentially more toxic agents such as the polymyxins (7). Although high carbapenem resistance rates have been reported among Acinetobacter spp. isolated in Brazil, very little is known about their mechanisms of resistance. Recently, it has been reported that IMP-1 metallo-beta lactamase-producing Acinetobacter strains emerged in 1998 in some Brazilian hospitals (15). Regarding OXA-type carbapenemases, only the bla $a_{\mathrm{OXA}-23}$-like gene has been associated with imipenem resistance in Brazil (6). We hereby report the combination of the naturally intrinsic harboured blaXA-51-like gene and impermeability as mechanism responsible for imipenem-resistant phenotype in clonally related
A. baumannii recovered from an outbreak, in a Brazilian teaching hospital.

From September 2005 to February 2006 eleven MDR, Acinetobacter baumannii isolates were recovered from six ICU patients hospitalized at the Hospital Universitário da Universidade de São Paulo (HU-USP). Species identification and antimicrobial susceptibility (Table 1) were evaluated using the Vitek system (BioMérieux, Hazlewood, Mo.) and the disk diffusion method, respectively. Molecular typing was performed by Pulsed Field Gel Electrophoresis (PFGE) of ApaI-digested genomic DNA of A. baumannii isolates (17). PFGE band profiles were identical for all carbapenem-resistant strains. Minimum inhibitory concentrations (MICs) for all isolates were determined by the agar dilution method (4). Additionally, some combinations antibiotic/ $\beta$-lactamase inhibitors were tested as follows: ceftazidime/clavulanic acid (4.0 mg/L) (4), imipenem/EDTA(320 $\mathrm{mg} / \mathrm{L})(22)$, imipenem/ $\mathrm{NaCl}(200 \mathrm{mM})(16)$. All strains were found to be resistant to more than 3 antimicrobial groups (Table 1), presenting MICs $\geq 32$ and $\geq 64 \mathrm{mg} / \mathrm{L}$ for imipenem and ceftazidime, respectively. The inhibitors tested did not affect MIC's values when associated with imipenem or ceftazidime.

*Corresponding Author. Mailing address: Laboratory of Clinical Microbiology, Faculdade de Ciências Farmacêuticas, Universidade de São Paulo, Av. Professor Lineu Prestes 580, Cidade Universitária. CEP 05508-000, São Paulo, SP, Brasil. E-mail: mbmartin@usp.br 
Takagi, E.H. et al.

Table 1. Antibiotic susceptibilities of the Acinetobacter baumannii strains in this study.

\begin{tabular}{ccccc}
\hline Case & Origin (Specimen) & Isolation date & Hospital unit & Antimicrobial susceptibility \\
\hline Case 1 & Urine & $05 / 09 / 2005$ & Adult ICU & none \\
Case 2 & Tracheal secretion & $11 / 01 / 2006$ & Adult ICU & ART \\
& Blood & $12 / 01 / 2006$ & Adult ICU & SAM, ART \\
Case 3 & Blood & $19 / 01 / 2006$ & Adult ICU & SAM \\
& Catheter tip & $19 / 01 / 2006$ & Adult ICU & SAM \\
& Catheter tip & $19 / 01 / 2006$ & Adult ICU & SAM \\
Case 4 & Abdominal secretion & $20 / 01 / 2006$ & Adult ICU & SAM \\
& Tracheal secretion & $24 / 01 / 2006$ & Adult ICU & SAM \\
Case 5 & Tracheal secretion & $31 / 01 / 2006$ & Adult ICU & SAM \\
& Blood & $02 / 02 / 2006$ & Adult ICU & SAM, FEP \\
Case 6 & Vaginal secretion & $10 / 02 / 2006$ & Adult ICU & SAM, FEP
\end{tabular}

Table captions: All strains were tested by Kirby Bauer method for: PIP, piperacillin; TZP, piperacillin/tazobactam; CAZ, ceftazidime; CTX, cefotaxime; FEP, cefepime; ATM, aztreonam; IMP, imipenem; MEM, meropenem; CIP, ciprofloxacin; AMK, Amikacin; GEN, Gentamicin; SXT, Trimethoprim/Sulfamethoxazole; ART, aztreonam; SAM, ampicillin/sulbactam; ICU, intensive care unit.

Research on carbapenemase production and outer membrane porin profile was performed using imipenem-susceptible and nonsusceptible isolates recovered from HU-USP.

Carbapenemase activity was evaluated using a bioassay (9). This test involved satellite growth of Staphylococcus aureus ATCC 25923 around the putative carbapenemaseproducing A. baumannii strains growing on Muller-Hinton agar plates containing $10^{8} \mathrm{CFU}$ of ATCC strain/mL and imipenem at a concentration of 0.06 or $0.12 \mathrm{mg} / \mathrm{L}$. Imipenemase activity was confirmed in all imipenem resistant isolates.

Metallo- $\beta$-lactamase (MBL) production was then screened by a double disk synergy test using ceftazidime and imipenem as substrates and EDTA and thiol compounds as $\beta$-lactamase inhibitors $(1,12)$. Imipenemase activity was not inhibited by EDTA or thiol compounds, suggesting that a serine-type $\beta$-lactamase was responsible for the hydrolysis of imipenem .

Imipenem-susceptible and resistant A. baumannii were screened by PCR for the $b l a_{\mathrm{IMP}}, b l a_{\mathrm{VIM}}, b l a_{\mathrm{SPM}-1}, b l a_{\mathrm{OXA}-23}-1$ ike, bla $a_{\text {OXA-24-like, }}$ bla $a_{\text {OXA-51-like and }}$ bla $a_{\text {OXA-58-like genes, as }}$

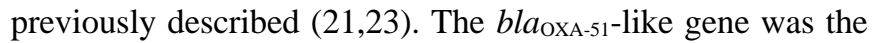
only one detected, even in imipenem-susceptible strain, confirming global reports of the intrinsic presence of class D carbapenemase in A. baumannii (10,20). ISAba1 was also found by PCR, but the insertion sequence was not upstream of the

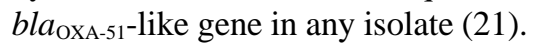

Alterations in permeability were evaluated by outer membrane porin (OMP) analysis in imipenem susceptible (MIC $0.5 \mathrm{mg} / \mathrm{L})$ and resistant $A$. baumannii isolates. The OMP fractions were prepared by the $N$-Lauryl-sarcosinate method (5). Total OMP concentration was measured according to Bradford (3). OMP profiles were analyzed by SDS-PAGE and showed absence of an expected $22 \mathrm{kDa}$ fraction in the imipenemresistant isolates.

A. baumannii is recognized as playing a significant role in the colonization and infection of hospitalized patients, especially those in critical care environments. The carbapenems, such as imipenem, have been widely used to treat infections caused by MDR A. baumannii clinical isolates, nevertheless, regrettably, carbapenem-resistant $A$. baumannii clinical isolates have become more prevalent. In this respect, impermeability or drug inactivation by carbapenemases belonging to metallo-betalactamase class B or some class D OXA-type enzyme subgroups have been described as major causes of resistance.

Additionally, a decrease in outer membrane permeability has been associated with resistance to carbapenems in A. baumannii clinical strains (15). It was associated to with the loss of $29 \mathrm{kDa}$ OMP (13), 31-36kDa (5), 25/29 kDa corresponding to the socalled CarO $(2,5,18,14)$. Thus, isolates with weak OXA carbapenemases could be required to bear additional codeterminants of resistance, in particular, the absence of outermembrane proteins as demonstrated by Costa et al. (5), whose resistant isolates had acquired two $\beta$-lactamases and had also lost a protein of 31-36 kDa. Bou et al. (2) report a multiresistant isolate that produce OXA-24 with reduced expression of two proteins $22 \mathrm{kDa}$, the same lacked protein in our isolate, and $33 \mathrm{kDa}$.

At the ICU from HU-USP, the outbreak involved eight cases of infection by a single RAPD-PCR clone. Carbapenem resistant phenotype was related to the lack of a $22 \mathrm{kDa}$ OMP and the

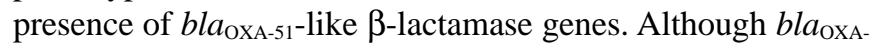
${ }_{51}$-like $\beta$-lactamase genes were the only ones identified, further studies are necessary to understand the role of these genes like resistance mechanism. 


\section{ACKNOWLEDGEMENTS}

FAPESP and CNPq research grants are gratefully acknowledged. E. H. Takagi thanks CNPq for an undergraduate fellowship.

\section{RESUMO}

\section{Caracterização de cepas de Acinetobacter baumannii durante um surto de infecção hospitalar}

Foram isoladas 19 cepas monoclonais de 8 pacientes da unidade de terapia intensiva, resistentes aos carbapenêmicos. Todas as cepas apresentaram o gene $b l a_{\mathrm{OXA}-51}$-like e por análise do perfil de proteínas de membrana notou-se ausência da fração de $22 \mathrm{kDa}$, sugerindo a combinação de dois mecanismos de resistência aos carbapenêmicos.

Palavras-chaves: Acinetobacter, bla $a_{\mathrm{OXA}}$-type genes, carbapenemases, infecção hospitalar

\section{REFERENCES}

1. Arakawa, Y.; Shibata, N.; Shibayama, K.; Kurokawa, H.; Yagi, T.; Fujiwara, H.; Goto, M. (2000). Convenient test for screening metallo$\beta$-lactamase-producing gram-negative bacteria by using thio compounds. J. Clin. Microbiol., 38, 40-43.

2. Bou, G.; Cerveró, G.; Domínguez, M.A.; Quereda, C.; MartinezBeltrán, J. (2005). Characterization of nosocomial outbreak caused by a multiresistant Acinetobacter baumannii strain with a carbapenem-hydrolyzing enzyme: high-level carbapenem resistance in A. baumannii is not due solely to the presence of $\beta$-lactamases. $J$. Clin. Microbiol., 38, 3299-3305.

3. Bradford, M.M. (1976) A rapid and sensitive method for the quantitation of microgram quantities of protein utilizing the principle of protein-dye binding. Anal. Biochem., 7, 248-254.

4. Clinical and Laboratory Standard Institute (2006). Performance standards for antimicrobial disk susceptibility tests. Approved standard M2-A9. Wayne, PA.

5. Costa, S.F.; Woodcock, M.G.; Wise, R.; Barone, A.A.; Caiaffa, H.; Levin, A.S.S. (2000) Outer-membrane proteins pattern and detection of $\beta$-lactamases in clinical isolates of imipenem resistant Acinetobacter baumannii from Brazil. Int. J. Antimicrob. Agents., 13, 175-182.

6. Dalla-Costa, L.M.; Coelho, J.M.; Souza, H.A.P.H.M.; Castro, M.E.S.; Stier, C.J.N.; Bragagnolo, K.L.; Rea-Neto, A.; Penteado-Filho, S.R.; Livermore, D.M. (2003) Outbreak of Carbapenem-Resistant Acinetobacter baumannii producing the OXA-23 enzuyme in Curitiba, Brazil. J. Clin. Microbiol., 41, 3403-3406.

7. Falagas, M.E.; Kasiakou, S.K.; Kofteridis, R.; Samonis, G. (2006). Effectiveness and nephrotoxicity of intravenous colistin for treatment of patients with infections due to polymyxin-onlysusceptible (POS) gram-negative bacteria. Eur. J. Clin. Microbiol. Infect. Dis., 25, 596-599.

8. Fernández-Cuenca, F.; Martínez-Martínez, L.; Conejo, M.C.; Ayala, J.A.; Perea, E.J.; Pascual, A. (2003) Relationship betweeen $\beta$-lactamase production, outer membrane protein and penicillin-binding protein profiles on the activity of carbapenems against clinical isolates of Acinetobacter baumannii. J. Antimicrob. Chemother., 53, 565-574.

9. Gots, J.S. (1945) The detection of penicilinase-producing properties of microorganisms. Science., 102, 309.

10. Heritier, C.; Poirel, L.; Fournier, P.E.; Claverie, J.M.; Raoult, D.; Nordmann, P. (2005). Characterization of the naturally occurring oxacillinase of Acinetobacter baumannii. Antimicrob. Agents Chemother., 49, 4174-4179.

11. Kiffer, C.; Hsiung, A.; Oplustiul, C.; Sampaio, J.; Sakayami, E.; Turner, P.; Mendes, C. (2005). Mystic Brazil Group. Antimicrobial susceptibility of gram-negative bacteria in Brazilian hospitals: the MYSTIC program Brazil 2003. Braz. J. Infect. Dis., 9, 216-224.

12. Lee, K.; Lim, Y.S.; Yong, D.; Yum, J.H.; Chong, Y. (2003). Evaluation of the Hodge Test and the imipenem-EDTA double-disk synergy test for differentiating metallo- $\beta$-lactase-producing isolates of Pseudomonas spp. and Acinetobacter spp. J. Clin. Microbiol., 41, 4623-4629.

13. Limansky, A.S.; Mussi, M.A.; Viale, A.M.; (2002). Loss of a 29kilodalton outer membrane protein in Acinetobacter baumannii is associated with imipenem resistance. J. Clin. Microbiol., 40, 47764778 .

14. Martí, S.; Sánchez-Céspedes, J.; Oliveira, E.; Bellido, D.; Giralt, E.; Vila, J. (2006) Proteomic analysis of a fraction enriched in cell envelope proteins of Acinetobacter baumannii. Proteomics., 6, 82-87.

15. Peleg, A.Y.; Seifert, H.; Paterson, D. (2008). Acinetobacter baumannii: emergence of a successful pathogen. Clin. Microbiol. Rev., 21, 538-582.

16. Pournaras, S.; Markogiannakis A.; Ilkonomidis, A.; Kondyli, L.; Benthimounti, K.; Maniatis, A.N.; Legakis, N.J.; Tsakris, A. (2006). Outbreak of multiple clone of imipenem-resistant Acinetobacter baumannii isolates expressing OXA-58 carbapenemase in an intensive care unit. J. Antimicrob. Chemother., 57, 555-561.

17. Seifert, H.; Dolzani, L.; Bressan, R.; Reijden, T.; Strijen, B.; Stefanik, D.; Heersma, H.; Dijkshoorn, L. (2005). Standardization and interlaboratory reproducibility assessment of Pulsed-Field gel electrophoresis-generated fingerprints of Acinetobacter baumannii. J. Clin. Microbiol., 43, 4328-4335.

18. Siroy, A.; Molle, V.; Lemaître-Guillier, C.; Vallenet, D.; Pestel-Caron, M.; Cozzone, A.J.; Jouenne, T.; Dé, E. (2005) Channel formation by $\mathrm{CarO}$, the carbapenem resistance-associated outer membrane protein of Acinetobacter baumannii. Antimicrob. Agents Chemother., 49 , 4876-4883.

19. Tognim, M.C.; Gales, A.C.; Penteado, A.P.; Silbert, S.; Sader, H.S. (2006) Dissemination of IMP-1 metallo-beta-lactamase-producing Acinetobacter species in a Brazilian teaching hospital. Infect Control Hosp. Epidemiol., 27, 742-747.

20. Turton, J.F.; Glover, J.; Yarde, S.; Kaufmann, M.E.; Pitt, T.L. (2006). Identification of Acinetobacter baumannii by detection of the

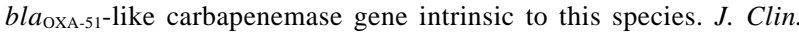
Microbiol., 44, 2974-2976.

21. Turton, J.F.; Ward, M.G.; Woodford, N.; Kaufmann, M.G.; Pike, R.; Livermore, D.M.; Pitt, T.L. (2006). The role of IsAba1 in expression of OXA carbapenemase genes in Acinetobacter baumannii. FEMS Microbiol. Lett., 258, 72-77.

22. Walsh, R.T.; Bolmström, A.; Qwärnström, A.; Gales, A. Evaluation of a new Etest for detecting metallo- $\beta$-lactamases in routine clinical testing. J. Clin. Microbiol., 40, 2755-2759.

23. Woodford, N.; Ellington, M.J.; Coelho, J.M.; Turton, J.F.; Ward, M.E.; Brown, S.; Amyes, S.G.B.; Livermore, D.M. (2006). Multiplex PCR for genes encoding prevalent OXA carbapenemaes in Acinetobacter spp. Int. J. Antimicrob. Agents., 27, 351-353. 